\title{
Multilevel models and scientific progress in social epidemiology
}

This manuscript places the emergence of multilevel statistical models into the context of a critical evaluation of the field of social epidemiology.

\section{Jeffrey B Bingenheimer}

\section{Formidable institutional barriers stand in the way of rigorous theory development in social epidemiology.}

\footnotetext{
l:
} novation in the technical means of empirical inquiry is a necessary and perhaps inevitable component of scientific progress. New tools not only allow investigators to study phenomena that had previously been inaccessible to them, but also permit them to look at existing phenomena in novel ways, and occasionally provide metaphors that serve as building blocks of original theory. ${ }^{12}$ Yet technical innovation also poses dangers. Among these is the possibility that people lacking the requisite training effectively will be excluded from meaningful participation in scientific discourse. As the methods of empirical research grow more specialised, those who have mastered their use may become increasingly insulated from the criticism of their peers. And science without criticism is bound to go badly. The question, then, is not whether technical innovation is good or bad, but rather how scientific disciplines can capitalise on such advances while simultaneously mitigating the attendant dangers.

Questions of this sort now face our field as social epidemiologists collectively seek to incorporate into our practices a comparatively new class of statistical models, referred to variously as multilevel, hierarchical, random effects, and mixed models. Certainly these models have a great deal to offer us, given our shared interest in exposures that occur at the community level but whose ultimate effects on health are mediated through physiological processes within individual bodies. In fact, multilevel models provide a highly flexible framework for studying a broad range of phenomena, and social epidemiology has just begun to scratch the surface of their potential applications. For many of us, however, statistical methods comprise some of the most difficult and least interesting aspects of our work. And some of us may find the investment of time and energy that would be required truly to master multilevel models to be simply prohibitive. As the use of multilevel models becomes more widespread, then, there is a danger that some of us will be left out of our field's evolving discourse, while others are tempted to use the technical complexity of their models to shield their work from critical evaluation.

In this issue of the journal, Merlo and his colleagues ${ }^{3}$ provide a tutorial-the first in a series - on multilevel models in social epidemiology. Theirs is far from the only tutorial on this topic to appear in the epidemiological literature. Indeed, the publications listed in their references section represent the tip of a large and growing iceberg of books and articles that have been written on multilevel models. This tutorial differs from its predecessors in being written on a more conceptual level. The authors present the material in the context of a simple simulated dataset, and provide several figures that may help readers achieve some visual intuition about the interpretation of multilevel models. Of course, no one will become an expert simply by reading this tutorial or even the whole series. But if these tutorials help to demystify multilevel models for some readers, then Merlo and his colleagues will have made a valuable contribution to preserving the inclusiveness of discourse in our field.

A second and perhaps more fundamental danger accompanying the incorporation of multilevel models into the practice of social epidemiology relates to the dominance of empirical work over theory development in our discipline. A glance at the table of contents of any epidemiology textbook shows, in essence, a list of study designs and statistical methods. ${ }^{4-7}$ What little theory we have is largely focused on the physiological mechanisms that transform exposures, be they at the individual or community level, into health outcomes. ${ }^{8}$ Virtually non-existent in our field is any systematic theory of the social and economic processes that generate health hazards and shape the distribution of exposures among people and populations. These processes are undoubtedly complex and dynamic, and will require theory that goes far

\section{Policy implications}

The manuscript implicitly suggests that institutional sources of funding for health research should provide more support for the development of social epidemiological theory.

beyond a few paragraphs in the background sections of empirical papers. This, in essence, was the message of Susser and Susser ${ }^{9}{ }^{10}$ when they issued their eloquent call, nearly 10 years ago, for a new paradigm to replace the "black box" approach to chronic disease epidemiology with a multilevel ecological perspective.

Formidable institutional barriers stand in the way of rigorous theory development in social epidemiology. Governmental and other funding sources are interested almost exclusively in supporting empirical research targeting specific health outcomes. Promotion, tenure, and other forms of professional recognition follow along the same lines. Yet somehow we social epidemiologists must find ways of rewarding serious theoretical work on a par with empirical work. For without strong theory we have little basis for knowing what parameters are truly worth measuring-what data to collect, what statistical models (multilevel or otherwise) to fit to them, and how to interpret the results. Continued progress of our field may depend more critically at this point upon our ability to promote theoretical innovation than upon our proper use of the latest statistical methodology.

\section{$J$ Epidemiol Community Health} 2005;59:438-439.

doi: $10.1136 /$ jech.2004.028456

Correspondence to: $\operatorname{Dr} J$ B Bingenheimer, Department of Health Behavior and Health Education, University of Michigan School of Public Health, 1420 Washington Heights, Ann Arbor, MI 48109-2029 USA; bartbing@umich. edu

\section{REFERENCES}

1 Gigerenzer G. From tools to theories: a heuristic of discovery in cognitive psychology. Psychol Rev 1991;98:254-67.

2 Gigerenzer G, Goldstein DG. Mind as computer: the birth of a metaphor. Creativity Research Journal 1996;9:131-44. 
3 Merlo J, Chaix B, Yang M, et al. A brief conceptual tutorial of multilevel analysis in social epidemiology: linking the statistical concept of clustering to the idea of contextual phenomenon. J Epidemiol Community Health 2005;59:443-9.

4 MacMahon B, Pugh TF. Epidemilogy: principles and methods. Boston: Little, Brown, 1970.
5 Lilienfeld AM, Lilienfeld DE. Foundations of epidemiology. 2nd ed. New York: Oxford University Press, 1980.

6 Hennekens $\mathrm{CH}$, Burning JE. Epidemiology in medicine. Boston: Little, Brown, 1987

7 Rothman KJ, Greenland S. Modern epidemiology. 2nd ed. Philadelphia: Lippincott Williams and Wilkins, 1998.
8 Berkman LF, Kawachi I. Social epidemiology. New York: Oxford University Press, 2000.

9 Susser M, Susser E. Choosing a future for epidemiology: I. Eras and paradigms. Am J Public Health 1996:86:668-73.

10 Susser M, Susser E. Choosing a future for epidemiology: II. From black box to Chinese boxes and eco-epidemiology. Am J Public Health 1996;86:674-7.

\section{Speaker's corner}

\section{Prevention neglect. A utopian vision or time for a new social health contract?}

S ince the founding of the medical contract, several series of ethical norms based on the Hippocratic oath (460-370 $\mathrm{BC})$ have been oriented to provide health care to those who are in need. The professional practice has generated some problems such as negligence (lack of due diligence or care; omission of duty; heedlessness), iatrogenia (disease produced as a consequence of medical or surgical treatment), or new modalities under the scope of the so called medical errors (http://www.ahrq.gov/qual/errorsix.htm).

When these problems are considered from the preventive point of view, the matter is not clearly solved, particularly in developing countries, where prevention has not reached a peak value. This gap can be explained by multiple factors and determinants that range from lack of health literacy to the absence of political awareness on the potential consequences of the omission of effective preventive interventions on a population's health.

From the individual perspective and for certain groups of diseases, a set of clinical preventive services can be provided by the health system with verified benefits ${ }^{1}$ : screening, immunisations/chemoprophylaxis, and counselling. Community based interventions ${ }^{2}$ and public policies were also validated in terms of their effectiveness. ${ }^{3}$

In developing countries, the right that a citizen has to claim for clinical preventive services or preventive public policies is not met with the same vehemence as with medical care. It is probable that both factors have a common denominator: absence of debate on setting health priorities and an impoverished society, especially in terms of civil rights.

Some vignettes coming from developing countries can enlighten the discussion: (1) 20 years ago, the death of a child by measles was accepted as "natural", (the same situation today can ignite an institutional-political conflict), ${ }^{4}$ (2) women dying because of lack of accessibility to screening programmes for cervix cancer as an expression of the inequity in the access to preventive care, (3) poor health attributable to lack of health literacy in sexual and reproductive health behaviours as a proxy indicator for low coverage in health counselling activities to prevent sexually transmitted infections, (4) lack of state policies and regulations against tobacco as the most important contributing factor for the dissemination of the tobacco epidemic. ${ }^{5}$

The question is: Can prevention needs be transformed into a human rights issue or, should the omission of effective preventive interventions be interpreted as a matter of negligence? Perhaps this is the moment to coin the term prevention neglect as an alternative concept to redefine the contract between policy makers, healthcare providers, and the community as a way to describe the cost of doing nothing.

Raúl Mercer

CEDES (Centre for Studies of State and Society), Sanchez de Bustamante 27, Buenos Aires, Argentina; rmercer@cedes.org

\section{REFERENCES}

1 US Preventive Services Task Force. Guide to clinical preventive services. 2nd ed. Town: Williams and Wilkins, 1996.

2 Dever AGE. Evidence-based public health practice. In: Improving outcomes in public health practice. Strategy and methods. New York: Aspen, 1997.

3 Peiró R, Alvarez Dardet C, Plasencia A, et al. Rapid appraisal methodology for 'health for all' policy formulation analysis. Health Policy 2002;62:309-28.

4 Interpelan al Ministro de Salud de la Provincia de Buenos Aires por el brote de sarampión. Diario El Día. Buenos Aires: Interpelan al Ministro de Salud de la Provincia de Buenos Aires, 1999.

5 World Health Organisation. WHO framework convention on tobacco control, $11^{\text {th }}$ conference on tobacco or health, 2000. 